\title{
ESR
}

\section{Role of virtopsy in the postmortem diagnosis of drowning}

\author{
Poster No.: $\quad$ C-1074 \\ Congress: $\quad$ ECR 2014 \\ Type: \\ Scientific Exhibit \\ Authors: $\quad$ F. Vernuccio, G. Lo Re, D. Picone, M. C. Galfano, A. Argo, S. \\ Zerbo, C. Sortino, P. Procaccianti, M. Midiri; Palermo/IT \\ Keywords: $\quad$ Forensic / Necropsy studies, CT, Medico-legal issues, Forensics \\ DOI: \\ 10.1594/ecr2014/C-1074
}

Any information contained in this pdf file is automatically generated from digital material submitted to EPOS by third parties in the form of scientific presentations. References to any names, marks, products, or services of third parties or hypertext links to thirdparty sites or information are provided solely as a convenience to you and do not in any way constitute or imply ECR's endorsement, sponsorship or recommendation of the third party, information, product or service. ECR is not responsible for the content of these pages and does not make any representations regarding the content or accuracy of material in this file.

As per copyright regulations, any unauthorised use of the material or parts thereof as well as commercial reproduction or multiple distribution by any traditional or electronically based reproduction/publication method ist strictly prohibited.

You agree to defend, indemnify, and hold ECR harmless from and against any and all claims, damages, costs, and expenses, including attorneys' fees, arising from or related to your use of these pages.

Please note: Links to movies, ppt slideshows and any other multimedia files are not available in the pdf version of presentations.

www.myESR.org 


\section{Aims and objectives}

Drowning is the third leading cause of unintentional injury death worldwide, accounting for $7 \%$ of all injury related deaths[1]. The autopsy diagnosis of drowning is one of the major problems in forensic medicine, especially when there is delay in recovering the corpse[2]. The main limit in the diagnosis of drowning is that even if a body is recovered from sea water, it may not have drowned and the proof that death was due to drowning may constitute a difficult problem to solve in forensic medicine. Due to the admitted limits of autopsy-based studies in the diagnosis of drowning, virtopsy is considered the new imaging horizon in these post-mortem studies[3-6]. The aim of our study was to evaluate the role of virtopsy performed through CT in forensic diagnosis of drowning.

\section{Methods and materials}

CT data of 4 cadavers (2 males, 2 females; mean age 34 years) recovered from sea water and suspected to have died by drowning were retrospectively examined. 2 of the cadavers were recovered after the air crash of a Tuninter ATR 72 which ditched off the coast of Palermo on the 6th of August 2005. The other 2 bodies were found in 2012 at Terrasini in an area of the sea overlooking a clifftop. Each cadaver underwent a full body postmortem-CT scan, and then a traditional autopsy.

\section{Results}

Characteristically, all the cadavers had fluid in the airways and patchy ground-glass opacities in the lungs (figure 1 and 2). 3 of the cadavers had fluid in the paranasal sinuses (figure 3). Only 1 patient did not show fluid in the digestive tract: this patient had left parietal bone fracture with a large gap; moreover, he had multiple bone fractures (nose, clavicle, first rib, femur and patella) (figure 4). 1 of the 3 patients with fluid in the digestive tract had not fluid in the paranasal sinuses. This latter cadaver showed cerebral edema with subarachnoid and intraventricular hemorrhage, multiple bone fractures (orbital floor, ribs, sacrum, acetabular edge) and air in the heart, in the aorta and in bowel loops.

The forensic reconstruction revealed that one of the two dead bodies fallen from a rocky cliff of 20 meters, despite having suffered a major head injury that led to the fracture of the zygomatic process and of the greater wing of sphenoid bone without significant brain lesion, did not die because of the head injury; these fractures indeed did not cause immediate death as demonstrated by the fact that sea water was present both in the airways and in the digestive tract. In the second patient who precipitated from the rocky cliff instead, the absence of fluid in the digestive tract and the presence of a skull fracture 
with significant brain lesion suggests that the primary cause of death in this patient occurred before the immersion in sea water.

Images for this section:

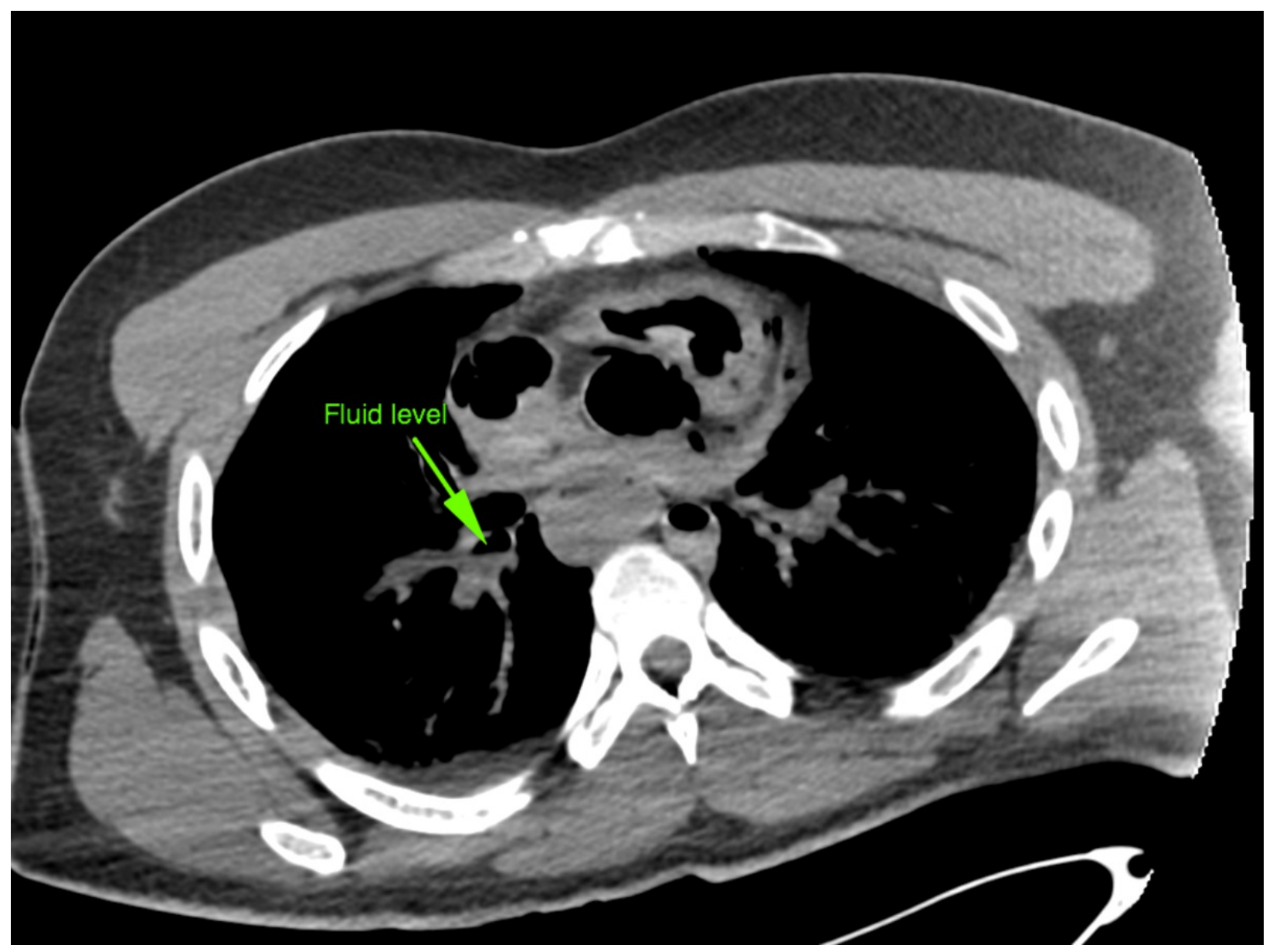

Fig. 1: CT scan shows fluid in the airways (see arrow). 


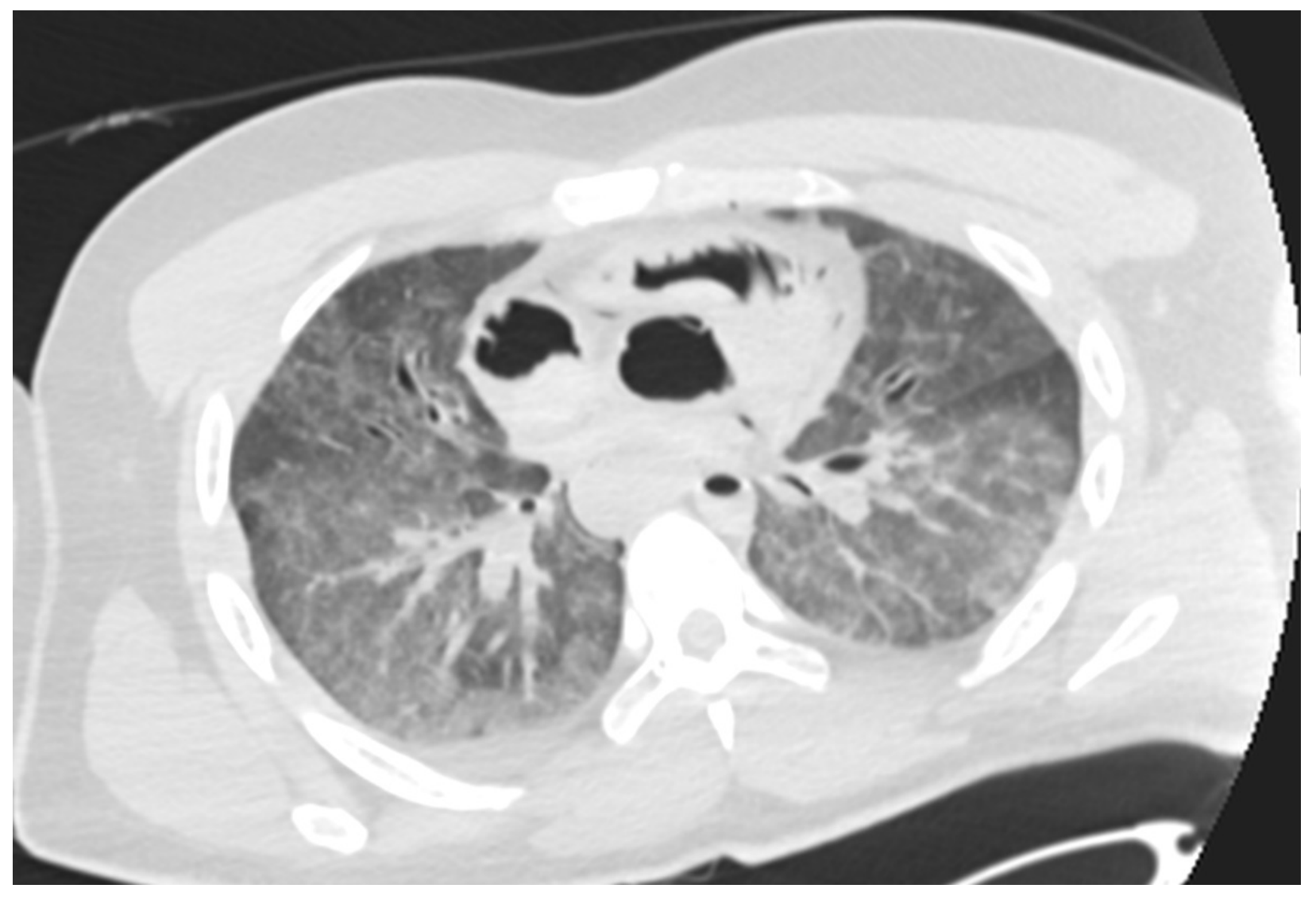

Fig. 2: CT shows ground-glass opacities in the lung parenchyma. 


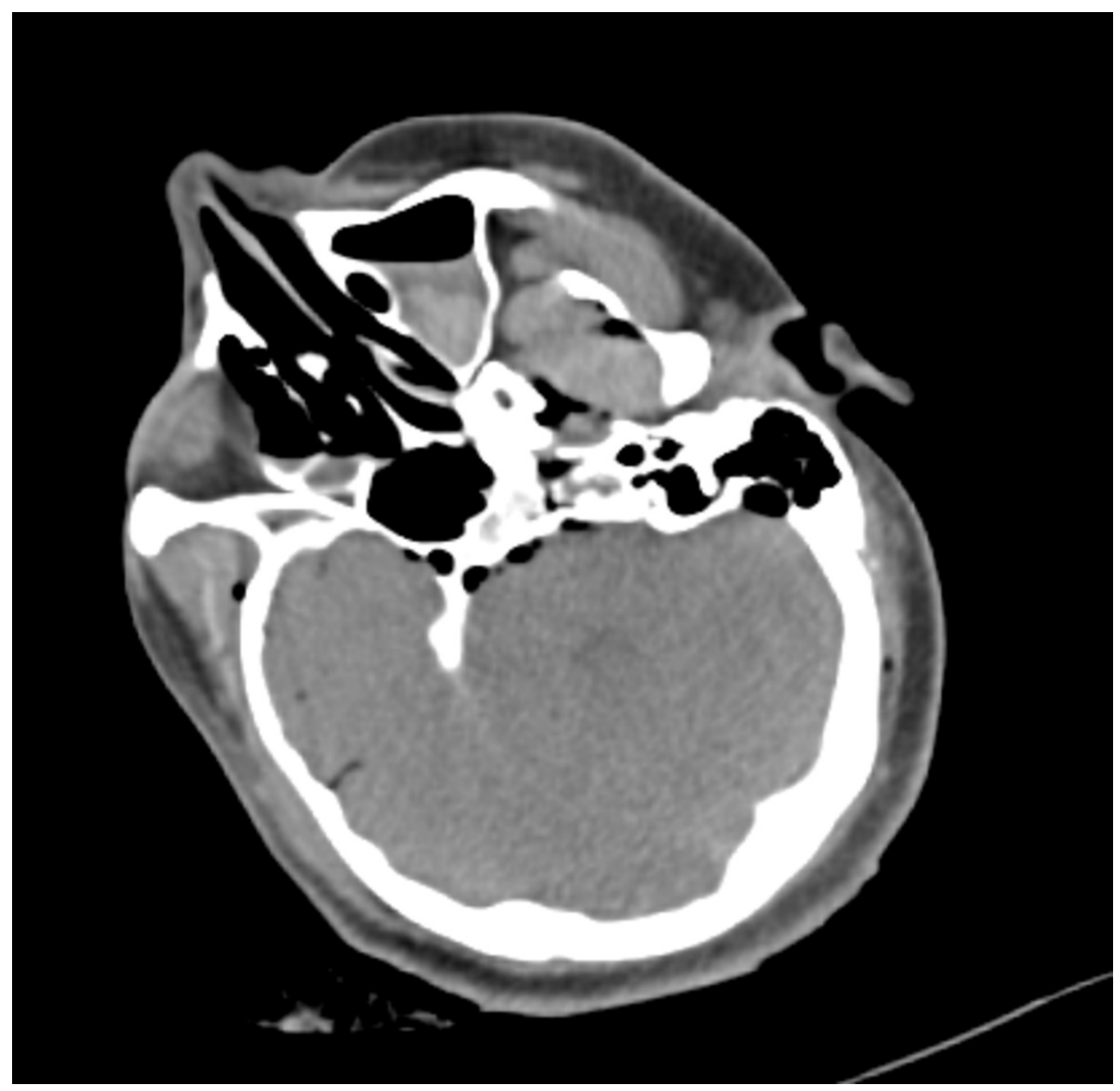

Fig. 3: CT showing fluid in the paranasal sinuses. 


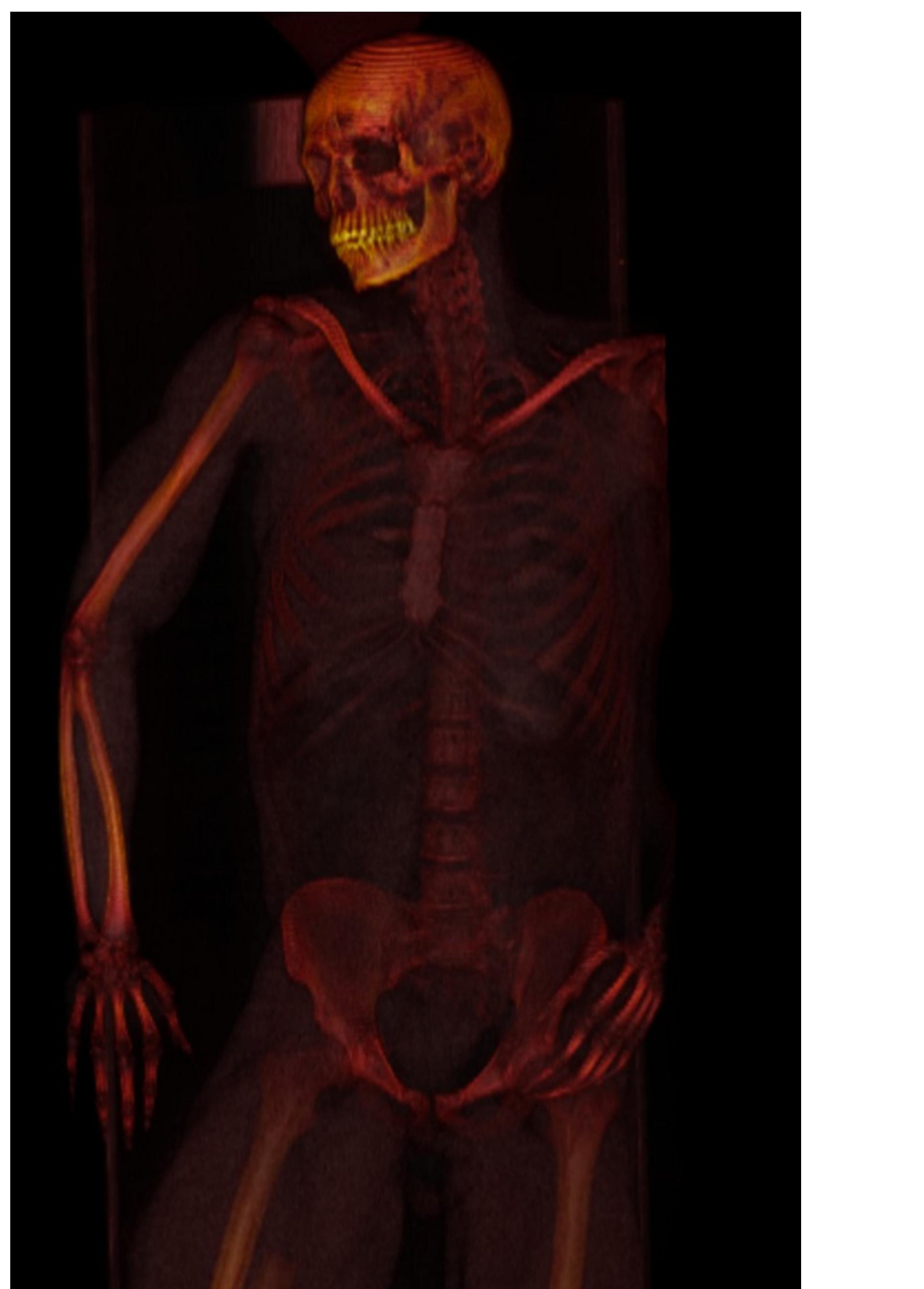


Fig. 4: 3D VR image shows right femur fracture. 


\section{Conclusion}

As widely known in literature, there are no autopsy findings pathognomic of drowning. This study shows that virtopsy may help understanding if the victim was alive or dead when he entered the water and if the cause of death was drowning. It is therefore clear that virtopsy can play a prominent role in the diagnosis of drowning, even if it is too early to predict whether it might replace classic autopsy.

\section{Personal information}

\section{References}

1 World Health Organization Fact sheet N347. Drowning. WHO, October 2012.

2. Piette MH, De Letter EA.Drowning: still a difficult autopsy diagnosis. Forensic Sci Int. 2006;163:1-9.

3. Thali MJ, Yen K, Schweitzer W, et al. Virtopsy, a new imaging horizon in forensic pathology: virtual autopsy by postmortem multislice computed tomography (MSCT) and magnetic resonance imaging (MRI)-a feasibility study. Journal of Forensic Sciences 2003;48:386-403.

4. Dirnhofer R, Fackowski C, Vock P, et al. Virtopsy: minimally invasive, imagingguided virtual autopsy. RadioGraphics 2006;26:1305-33.

5. Kawasumi $Y$, Kawabata T, Sugai $Y$, Usui A, Hosokai $Y$, Sato M, Saito H, Ishibashi T, Hayashizaki Y, Funayama M. Diagnosis of drowning using post-mortem computed tomography based on the volume and density of fluid accumulation in the maxillary and sphenoid sinuses. Eur J Radiol. 2013;82:e562-6.

6 Christe A, Aghayev E, Jackowski C, Thali MJ, Vock P. Drowning--post-mortem imaging findings by computed tomography. Eur Radiol. 2008;18:283-90. 